\title{
A Relationship Structure Analysis of the Reasons for College Students' Lack of Self-management Ability
}

\author{
Jia Li, Jing Li *, Bin Dou \\ School of Management and Economics \\ Kunming University of Science and Technology \\ Kunming, Yunnan 650093, China
}

\begin{abstract}
At present, due to the lack of self-management experience, college students do not have enough self-management ability. They are easy to be induced by the bad social atmosphere, which has a negative effect on their future life journey. Based on the theory and method of system engineering, this paper constructs the explanation structural model for college students' lack of self-management ability. It reveals the relationship structure among the 13 reasons for the lack of self-management ability of college students and finds out the source, surface and root reasons which affect the lack of self-management ability of them. In the meanwhile, it proposes some corresponding strategies, which will eventually provide some references to improve college students' self-management ability.
\end{abstract}

Keywords-college students; self-management ability; reason for the lack; system engineering; interpretation structure model

\section{INTRODUCTION}

With the development of society and economy, higher education in China has also experienced rapid development. On the one hand, our country has higher requirements for college students' quality. The cultivation and improvement of college students' self-management ability have gradually become one of the educational goals of college administrators. On the other hand, due to the expansion of enrollment, the scale of college students is enlarged continually. In order to meet the needs of social development, the reform of the higher education system has been gradually deepened. Credit institution has been promoted and the traditional class management has been weakened, which result in the traditional university management model become not suitable for the new trend of education development. The problem of college students' lack of self-management ability has been apparent. For example, some college students emphasis personality too much and lack cooperation spirit; some college students even do not have clear learning objectives and lack of self-learning awareness; other problems include the poor self-care ability and poor health habits, etc. Just like what the media has reported repeatedly on the bad behaviors of college students: some students send dirty clothes home with express delivery; some students raise pets in the dormitory; college students died suddenly in the Internet bar and so on. These negative phenomena have brought severe challenges to the education management of college administrators. The management of college students has become one the focus of the attention of college and university, education system and different fields in the society.

For the management of colleges and universities, strengthening the self-management of college students is an important part. At present, due to the lack of self-management experience of college students, the standard of self-management ability is insufficient. Therefore, college students' who are lack of self-management ability are easy to be induced by the bad social atmosphere, which will exert negative influence for them to build the quality of bravery, self-confidence, honesty and sense of responsibility. Therefore, the development of college students' self-management ability plays an important role in cultivating the comprehensive quality of college students. As a carrier of college students' growth, colleges and universities are responsible for educating. Therefore, how to cultivate college students to develop good habits and improve their self-management ability has become an important mission for the administration work of college and university, which needs to be settled urgently. This paper analyzes and summarizes the reasons for the insufficient self-management ability of college students by using the explanatory structure model, and then studies the factors that lead to the insufficiency.

\section{CONSTRUCTION OF THE INTERPRETIVE STRUCTURAL MODEL FOR THE REASON ABOUT COLLEGE STUDENTS’ LACK of SELF-MANAGEMENT ABILITY}

\section{A. A brief introduction to the interpretive structural model}

Interpretive Structural Modeling (ISM) was proposed by J. Warfield from US in 1973 as a method for analyzing complex problems in social economic systems, which is featured with subsystems by decomposing complex systems. With the experience and knowledge in practice and the help of computers, a structural model with multilevel hierarchies will be eventually formed.

ISM is a conceptual model, which can transform ambiguous thoughts and ideas into intuitive models with good structural relationships. Therefore, it can be widely used, from the international issues to regional economic development, enterprises and even individual issues and etc. ISM can be used to build a structural model to analyze systems which have complex relationships and unclear structures. 
B. The determination of the reasons for college students' lack of self-management ability

By analyzing some related papers [1-10], this paper analyses and conclude 13 main reasons for the lack of self-management of college students. As shown in table I. Among them, $S_{0}$ is set to be the key question for the research: college students' lack of self-management ability.

TABLE I. 90s COLLEge StUdents’ LACK OF SELF-MANAGEMENT ABILITy

\begin{tabular}{|c|c|c|c|}
\hline No. & Reasons & No. & Reasons \\
\hline$S_{1}$ & Most of 90s college students are single child ${ }^{[1]}$ & $S_{8}$ & The influence of examination methods ${ }^{[4]}$ \\
\hline$S_{2}$ & Parents' mistakes in money management ${ }^{[2]}$ & $S_{9}$ & $\begin{array}{l}\text { The psychological development of college students is in a } \\
\text { "transition period" }{ }^{[1]}\end{array}$ \\
\hline$S_{3}$ & Parents' mistakes in time management ${ }^{[2]}$ & $S_{10}$ & College students lack of management concepts ${ }^{[3]}$ \\
\hline$S_{4}$ & Two extreme management methods of parents ${ }^{[3]}$ & $S_{11}$ & The prevailing of non-mainstream culture in society ${ }^{[6]}$ \\
\hline$S_{5}$ & The university system can't keep pace with the time ${ }^{[3]}$ & $S_{12}$ & The popularization of the network culture ${ }^{[8]}$ \\
\hline$S_{6}$ & Professional training programs are not reasonable ${ }^{[4]}$ & $S_{13}$ & $\begin{array}{l}\text { Negative effects of factors such as utilitarianism in the period of } \\
\text { social transformation }{ }^{[6]}\end{array}$ \\
\hline$S_{7}$ & $\begin{array}{l}\text { Schools pay much attention to cultural education and ignore quality } \\
\text { cultivation }^{[5]}\end{array}$ & & \\
\hline
\end{tabular}

C. The determination of the relationship among the reasons.

In order to establish an explanatory structure model, the first step is to determine the mutual influence relationship among various factors. The criteria for determining the relationship is showed as follows:

1) $S_{i}$ has an effect on $S_{j}$, element in the corresponding position takes a value of 1 ; if $S_{i}$ has no effect on $S_{j}$, the element of the corresponding position takes a value of 0 $(i, j=0,1,2, \cdots, 13$ ) .

2) For those elements that have influence on each other, take the one with the greater influence as the influence relationship and it has an impact. Then, based on the mutual influence relationship among the various factors, establish an adjacency matrix $A$

$\left.\begin{array}{c|cccccccccccccc}S_{0} & 1 & 0 & 0 & 0 & 0 & 0 & 0 & 0 & 0 & 0 & 0 & 0 & 0 & 0 \\ S_{1} & 1 & 1 & 1 & 1 & 0 & 0 & 0 & 0 & 0 & 0 & 0 & 0 & 0 & 0 \\ S_{2} & 1 & 0 & 1 & 0 & 0 & 0 & 0 & 0 & 0 & 0 & 0 & 0 & 0 & 0 \\ S_{3} & 1 & 0 & 0 & 1 & 0 & 0 & 0 & 0 & 0 & 0 & 0 & 0 & 0 & 0 \\ S_{4} & 1 & 0 & 0 & 1 & 1 & 0 & 0 & 0 & 0 & 0 & 0 & 0 & 0 & 0 \\ S_{5} & 1 & 0 & 0 & 0 & 0 & 1 & 1 & 1 & 1 & 0 & 1 & 0 & 0 & 0 \\ S_{6} & 1 & 0 & 0 & 0 & 0 & 0 & 1 & 0 & 0 & 0 & 1 & 0 & 0 & 0 \\ A=S_{7} & 1 & 0 & 0 & 0 & 0 & 0 & 0 & 1 & 0 & 0 & 1 & 0 & 0 & 0 \\ S_{8} & 1 & 0 & 0 & 1 & 0 & 0 & 0 & 1 & 1 & 0 & 1 & 0 & 0 & 0 \\ S_{9} & 1 & 0 & 0 & 0 & 0 & 0 & 0 & 0 & 0 & 1 & 0 & 0 & 0 & 0 \\ S_{10} & 1 & 0 & 1 & 1 & 0 & 0 & 0 & 0 & 0 & 0 & 1 & 0 & 0 & 0 \\ S_{11} & 1 & 0 & 1 & 0 & 0 & 0 & 0 & 0 & 0 & 1 & 0 & 1 & 0 & 0 \\ S_{12} & 1 & 0 & 0 & 1 & 0 & 0 & 0 & 0 & 0 & 1 & 0 & 0 & 1 & 0 \\ S_{13} & 1 & 0 & 0 & 0 & 0 & 0 & 1 & 1 & 0 & 1 & 0 & 0 & 0 & 1\end{array}\right]$

\section{The division for the hierarchical relationship among factors}

According to the calculation formula of the accessibility matrix: $M=(A+I)^{4}=(A+I)^{3} \neq(A+I)^{2}$, the accessibility matrix $M$ is obtained. Among them, $A$ is the adjacency matrix, $I$ is a 14-order identity matrix.

\begin{tabular}{|c|c|c|c|c|c|c|c|c|c|c|c|c|c|}
\hline$S_{0}[$ & & 0 & 0 & 0 & 0 & 0 & 0 & 0 & 0 & 0 & 0 & 0 & 0 \\
\hline$S_{1}$ & 1 & 1 & 1 & 1 & 0 & 0 & 0 & 0 & 0 & 0 & 0 & 0 & 0 \\
\hline$S_{2}$ & 1 & 0 & 1 & 0 & 0 & 0 & 0 & 0 & 0 & 0 & 0 & 0 & 0 \\
\hline$S_{3}$ & 1 & 0 & 0 & 1 & 0 & 0 & 0 & 0 & 0 & 0 & 0 & 0 & 0 \\
\hline$S_{4}$ & 1 & 0 & 0 & 1 & 1 & 0 & 0 & 0 & 0 & 0 & 0 & 0 & 0 \\
\hline$S_{5}$ & 1 & 0 & 1 & 1 & 0 & 1 & 1 & 1 & 1 & 0 & 1 & 0 & 0 \\
\hline$S_{6}$ & 1 & 0 & 1 & 1 & 0 & 0 & 1 & 0 & 0 & 0 & 1 & 0 & 0 \\
\hline$S_{7}$ & 1 & 0 & 1 & 1 & 0 & 0 & 0 & 1 & 0 & 0 & 1 & 0 & 0 \\
\hline$S_{8}$ & 1 & 0 & 1 & 1 & 0 & 0 & 0 & 1 & 1 & 0 & 1 & 0 & 0 \\
\hline$S_{9}$ & 1 & 0 & 0 & 0 & 0 & 0 & 0 & 0 & 0 & 1 & 0 & 0 & 0 \\
\hline$S_{10}$ & 1 & 0 & 1 & 1 & 0 & 0 & 0 & 0 & 0 & 0 & 1 & 0 & 0 \\
\hline$S_{11}$ & 1 & 0 & 1 & 0 & 0 & 0 & 0 & 0 & 0 & 1 & 0 & 1 & 0 \\
\hline$S_{12}$ & 1 & 0 & 0 & 1 & 0 & 0 & 0 & 0 & 0 & 1 & 0 & 0 & 1 \\
\hline$S_{13}$ & & 0 & 1 & 1 & 0 & 0 & 1 & 1 & 0 & 1 & 1 & 0 & 0 \\
\hline
\end{tabular}

We can classify the hierarchies the accessibility matrix $M$ by suing ISM-array operation method. Firstly, calculate reduced accessibility matrix of the accessibility matrix $M$. Since there is no same element in corresponding row and column in $M$, so $M$ is the reduced accessibility matrix. Secondly, change the diagonal element to 0 , the matrix $M^{\prime}$ is obtained and the corresponding elements for the row which are all 0 in $M^{\prime}$ should be $\mathrm{f}_{\text {ound: }} S_{0}$, and $S_{0}$ becomes the first-level cause set, that is $L_{1}=\left\{S_{0}\right\}$; then, scratch out the corresponding row and column for $S_{0}$ and find out the elements corresponding to all the rows in the matrix of 0 , 
which is $S 2, S 3$, then $S 2, S 3$ constitutes the second-level set of cause elements, it is $L_{2}=\left\{\mathrm{S} 2 . S_{3}, S_{9}\right\}$.

\begin{tabular}{|c|c|c|c|c|c|c|c|c|c|c|c|}
\hline$S_{0}[$ & & 0 & 0 & 0 & 0 & 0 & 0 & 0 & 0 & 0 & 0 \\
\hline$S_{1}$ & 1 & 0 & 1 & 1 & 0 & 0 & 0 & 0 & 0 & 0 & c \\
\hline$S_{2}$ & 1 & 0 & 0 & 0 & 0 & 0 & 0 & 0 & 0 & 0 & c \\
\hline $\mathrm{S}_{3}$ & 1 & 0 & 0 & 0 & 0 & 0 & 0 & 0 & 0 & 0 & 0 \\
\hline$S_{4}$ & 1 & 0 & 0 & 1 & 0 & 0 & 0 & 0 & 0 & 0 & 0 \\
\hline$S_{5}$ & 1 & 0 & 1 & 1 & 0 & 0 & 1 & 1 & 1 & 0 & 1 \\
\hline$M^{\prime}=S_{6}$ & 1 & 0 & 1 & 1 & 0 & 0 & 0 & 0 & 0 & 0 & 1 \\
\hline $\mathrm{S}_{7}$ & 1 & 0 & 1 & 1 & 0 & 0 & 0 & 0 & 0 & 0 & 1 \\
\hline$S_{8}$ & 1 & 0 & 1 & 1 & 0 & 0 & 0 & 1 & 0 & 0 & 1 \\
\hline$S_{9}$ & 1 & 0 & 0 & 0 & 0 & 0 & 0 & 0 & 0 & 0 & 0 \\
\hline$S_{10}$ & & 0 & 1 & 1 & 0 & 0 & 0 & 0 & 0 & 0 & 0 \\
\hline$S_{11}$ & & 0 & 1 & 0 & 0 & 0 & 0 & 0 & 0 & 1 & 0 \\
\hline$S_{12}$ & & 0 & 0 & 1 & 0 & 0 & 0 & 0 & 0 & 1 & 0 \\
\hline$S_{13}$ & & 0 & 1 & 1 & 0 & 0 & 1 & 1 & 0 & 1 & 1 \\
\hline
\end{tabular}

$$
\begin{gathered}
L_{3}=\left\{S_{1}, S_{4}, S_{10}, S_{11}, S 12\right\} \\
L_{4}=\{S 6, S 7\} \\
L_{5}=\left\{S_{8}, S_{13}\right\} \\
L_{6}=\left\{S_{5}\right\}
\end{gathered}
$$

\section{E. Explanation the construction of structural models}

According to the set of factors at all levels in Section 2.4, an explanatory structure model for the reasons of college students' the lack of self-management ability is established, as shown in the fig.1. that is

In the same way, the remaining elements can be layered,

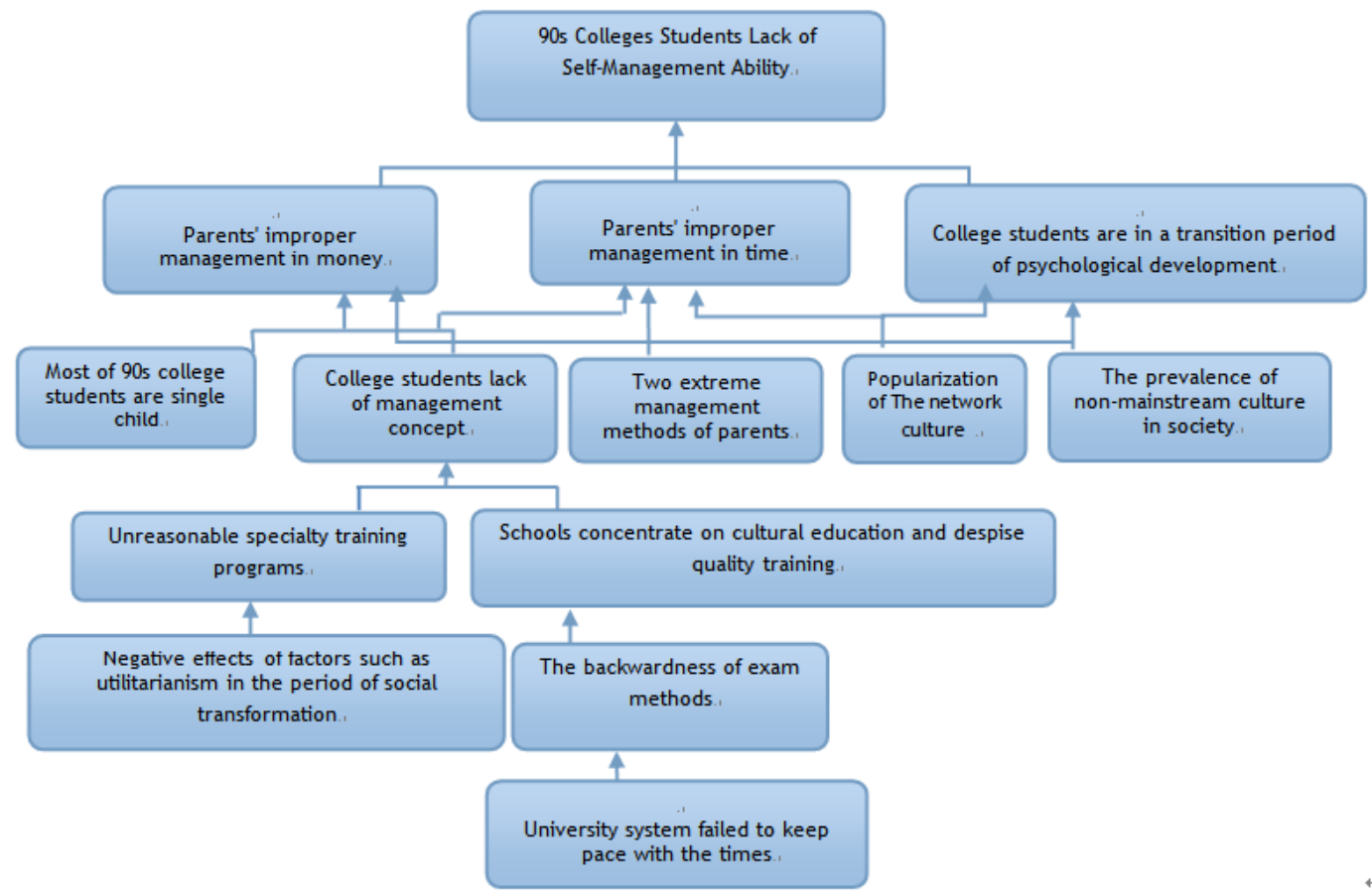

Fig.1 Interpretation structure model for the reasons of college students' lack of self-management

\section{INTERPRETATIVE ANALYSIS OF STRUCTURAL MODEL}

From the explanatory structure model for the reasons of college students' lack of self-management ability (Fig. 1), we know that the reason factors constitute a multiple level hierarchical structure model with 6 levels. This section will focus on reasons of college students' lack of self-management ability.

Through the overall analysis of the model, we can know:

The primary reasons lead to the lack of self-management ability of college students are: most of the 90s college students are the only child; the two extreme management methods of parents; the prevalence of network culture and non-mainstream culture in society; negative influence of factors such as utilitarianism in the period of social transformation; the university system can't keep pace with the times. Among them, the 90s college students are the only child, the prevalence of network culture and non-mainstream culture in society, the negative influence of factors such as utilitarianism in the period of social transformation belong to the uncontrollable elements of the lack of self-management ability of college students. The two extreme management methods of parents, the university system failed to keep up with the times are 
controllable elements. Since the primary causes are not affected by other factors, it is the source for the lack of self-management ability of college students. Therefore, these factors are also the key factors that cause the lack of self-management ability of college students. It is necessary to take actions according to those reasons to improve the self-management of college students.

By hierarchical analysis of the relationship structure of the model, we can understand that:

The reasons for the lack of self-management ability of college students are the second-level factor, that is the unreasonable money and time management of parents, and the psychological development of students is in the transition stage. Since most of the 90s college students are single child in their families, parents may have inappropriate behaviors in the management of their child in different aspects. For example, in the management of money, college students have rich university life and various entertainments are full of their lives. Before going to college, money is under the supervision of parents. But the life in the university stage is completely controlled by college students, which will easily cause the inappropriate management of money. In terms of time management, parents used to arrange time for their children excessively before they went to college, which leads it difficult for college students to form an independent time management concept. Also, the prevalence of online and non-mainstream culture has some negative influence during their psychological transition period to some extent. It can be observed that parents' unreasonable money and time management and students' psychological development in the transition period are the most direct and superficial reasons for the lack of self-management ability of college students.

The fundamental reasons for college students' lack of self-management ability, the bottom element, are the university system cannot keep pace with the times. Due to the exam-oriented education in the education system of China, school's education must take exams in the center place. And Education model is based on the teaching of test-based knowledge, while the quality education of students is ignored. School won't grant any rights to the students because they are afraid of self-management will be in trouble. Due to the backwardness of the school education system, the examination entirely relies on textbook knowledge, while the comprehensive quality and their social practice ability are ignored. Moreover, the backwardness of the college and universities' system lead to the situation that the primary education is exam-oriented, putting the enrollment rate of higher education as the first place, which results in the neglect of quality education at all stages of education. All of these lead to college students' lack of self-management ability.

\section{SugGestions AND COUNTERMEASURES}

Combining the analysis above, this section arises some corresponding countermeasures here for the primary and fundamental reasons of college students' lack of self-management ability: (1) The university system cannot keep pace with the times: To promote the institutional transformation of universities, government and society must make efforts together. First, the government must formulate long-term plans for the development of the university, providing certain financial and policy preferential treatment for the transformation of the university. And society must change the concept of success, the success of people cannot be judged by money or authority, but a good character can, which will promote the transformation of the university system. (2) For the prevalence of online culture and non-mainstream culture in society, it is necessary for government to strengthen the reviews in the process of cultural transaction to reduce the impact of unhealthy culture on college students, which will eventually improve their self-management ability. (3) In the management of the family, it is necessary for parents to manage their children more scientific and reasonable way. The two extreme management methods, totally control or never control, are not adoptive. (4) The negative effects of the factors such as utilitarianism in the period of social transformation. As the inevitable outcome of economic development, the existence of utilitarianism is reasonable. But if we want to reduce the negative effects of this kind of mind on college students, not only must school make efforts, but also the college students shall develop a correct view towards life.

\section{V.CONCLUSION}

With the development of society and economy, our country has higher requirements for the quality of college students. The cultivation and improvement of college students' self-management ability have gradually become one of the educational goals of college administrators. As a carrier of college students' growth, colleges and universities are responsible for the mission of educating people. Based on the theory and method of system engineering, this paper constructs the interpretative structural model of the reasons for college students' lack of self-management ability. With the analysis and conclusion about the reasons for the insufficient self-management ability by using explanatory structure model, this paper reveals the relationships structure among the 13 reasons for college students' lack of self-management ability. In the future step, it finds out that the reasons for the lack of self-management ability of college students form a multilevel hierarchical structure model with 6 levels. And the reasons for the lack of self-management ability of college students have a deep relationship with parents' management, network and social culture, as well as the university education system. The explanation structure model clarifies the influencing factors of the self-management ability of the university students from ambiguous concept to a specific one, which indicates the source, surface, and root reasons more directly and clearly. Based on the corresponding reasons, this paper brings some suggestions for the cultivation of self-management ability of college students, which is expected to provide some theoretical support for the future cultivation of college students and the high-quality talents output for society.

\section{REFERENCES}

[1] Wu Kongyang, Yang Wei, Yan Yafang, Du Ruyue. The Self-management Path of College Students Driven by the Innovation and Entrepreneurship Training Program and Its Influence on Students' Ability[J]. Science and Economics Guide, 2018, 26(36): 102-103. 
[2] Wang Juxing. Research on the Cultivation of College Students' Self-management Ability in the Age of Media[J]. Education Modernization, 2019, 6(29): 237-238.

[3] Wu Haisheng, Miao Yadong, Xu Haijiang, Liu Zhuping. Significance and Methods of Self-management of Applied Undergraduate College Students[J]. Education Modernization, 2018, 5(51): 276-277.

[4] Wang Wei. Research on College Students' Self-management Ability-Taking the Dormitory Management of Accounting Institute as an Example [J]. Farm Staff, 2018(24):173.

[5] Rong Meisheng, Ming Lijuan, Ma Wenjing, Li Yuyun, Xiong Yunbo. Research on the Cultivation of College Students' Self-management Ability under the Background of Multiculturalism[J]. New western(Mid Journal), 2015(3):126-129.

[6] Bian Ting, Zhang Liu Ting. Management and Self-management of College Students [J]. Academic Weekly, 2018 (32): 185-186.
[7] Fu Yue. From Management to Self-management-The Rationa Reconstruction of College Students' Subjectivity[J]. Journal of Chongqing Radio \& TV University, 2018, 30(04):30-34.

[8] Zhou Dang, Lu Xingtan. Research on the Self-management Ability of 90s College Students[J]. Journal of Liaoning University of Technology(Social Science Edition), 2018, 20(03):94-96.

[9] Pinto, Loureiro, Taveira, Psychological Intervention in Portuguese College Students: Effects of Two Career Self-Management Seminars[J]. JOURNAL OF COLLEGE STUDENT DEVELOPMENT, 2015 (60)518-524.

[10] Park Zhelong. The Structural Relationship of Self-Leadership, Self-Management, Self-Esteem and Life-Satisfaction[J]. Journal of Sport and Leisure Studies, 2015(56):105-11. 